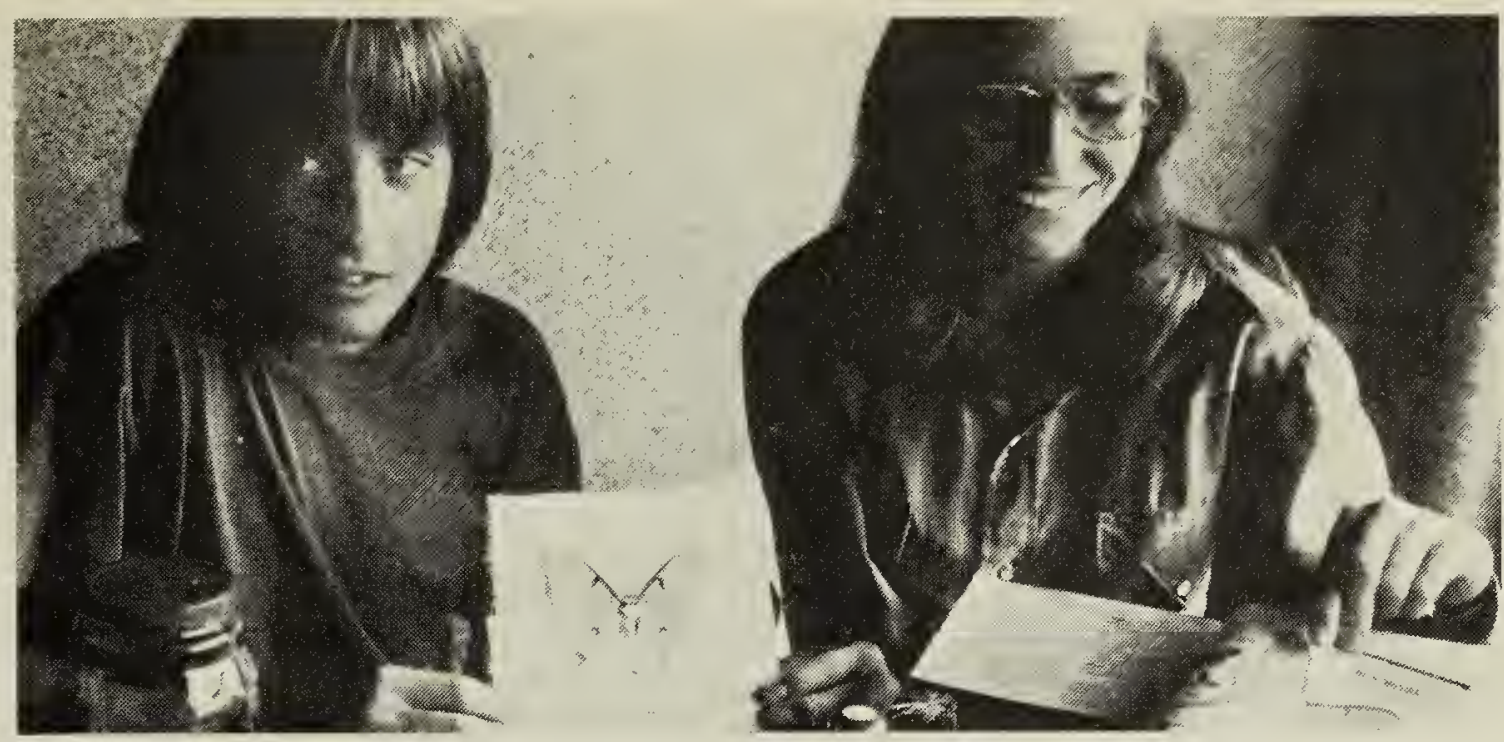

Gerry and Louise Couture with Luna Moth

F. J. Roy

\section{WESTERN RECORD FOR LUNA MOTH}

FRANK J. ROY,

1702 Sommerfeld Ave.,

Saskatoon, Sask. S7H 2S8

About 10:30 on the night of June 6 , 1975, Gerry Couture (then 13 years old) was surprised to see what he thought was a large leaf flapping by itself on a raspberry bush in the back yard. Walking closer, he changed his mind; it must be a hummingbird, he thought. But a closer look revealed that it was a large green moth, with wings so fresh and moist that Gerry concluded it had just emerged from a cocoon. Realizing that he had never seen an insect like this before, he called to his sister, Louise. Struck by its beauty, Gerry and Louise captured it using an ordinary quart-size pickle jar.

Soon brothers and sisters, by now distracted from their favorite TV program, were digging into every encyclopedia and natural history book in the house. In a matter of minutes they had identified the moth to their satisfaction.

The next day, their mother, Gay Couture, phoned to tell me the kids had a Luna Moth at the house. "Would you like to see it?" she asked. Not wanting to confess my doubts, I agreed to go over to 2613 Estey Drive.

Still alive, the moth was clinging to a branch the children had placed in the jar. It was a Luna in nearly perfect condition, with a wingspread of over 4-1/2 inches. Recognizing that the tails on the hind wings would soon be damaged, we killed it by applying spot remover to a wad of cotton batting and inserting it in the jar. With the help of Paul Coutu, a friend who had come over, we pinned the moth temporarily to a makeshift pinning board.

The next afternoon, Maurice Taylor of the Canada Department of Agriculture Research Station on the University campus positively identified the moth and pinned it properly. Checking the extensive collection at the Research Station, he noted that it did not yet contain a Luna Moth from Saskatchewan. He advised me then to write to Ottawa to determine the significance of Gerry's specimen.

Mr. W. C. McGuffin of the Biosystematics Research Institute in Ottawa confirmed in a letter dated August 12, 1975, that "Mr. Couture's capture represents a new locality record for this species." Adding that the Luna Moth has been collected in the Prince Albert and Hudson Bay areas of Saskatchewan, he concluded, "The Saskatoon record probably represents a western limit of range to date.'

Two perceptive young people, Gerry and Louise Couture, recognizing a rarity when they spotted it, have added to our knowledge of the range of one of its most beautiful inhabitants - the Luna Moth. 